\title{
Experimental Investigation on Use of Methyl Ester Kusum Oil and Its Blends In Direct Injection Ci Engine
}

\author{
N.P.Rathod ${ }^{1}$, S.M.Lawankar ${ }^{2}$ \\ ${ }^{I}$ M.Tech student, Thermal Engineering Govt. College of engineering,Amravati, \\ ${ }^{2}$ Asst. professor, Department of Mechanical Engineering Govt. College of engineering, Amravati.
}

\begin{abstract}
The research on alternative fuels for compression ignition engine has become essential due to depletion of petroleum products, higher oil prices and its major contribution for pollutants, where vegetable oil promises best alternative fuel. Vegetable oils, due to their agricultural origin, are able to reduce net $\mathrm{CO}_{2}$ emissions to the atmosphere. In the present paper, the research efforts directed towards improving the performance of C.I. engine using vegetable oil (Methyl ester kusum oil) as a fuel. The paper deals with results of performance of a single cylinder, four stroke, C.I. engine using kusum oil methyl ester and its blends with diesel. The performance of engine was studied at constant speed, with the engine operated at various loading conditions. Performance parameters considered for comparing are brake specific fuel consumption, thermal efficiency, brake power, exhaust gas temperature, smoke density and part load and peak load performance of the engine. The engine offers increase in thermal efficiency when it is powered by kusum oil and its blends at various loads. The power developed and exhausts gas temperature increases with the increase and specific fuel consumption is higher than diesel fuel.
\end{abstract}

\section{Introduction}

Diesel engine is a popular prime mover for transportation, agricultural machinery and industries. Diesel fuel is largely consumed by the transportation, industry and agricultural sectors. The consumption of diesel oil is several times higher than that of petrol. Import of petroleum products is a major drain on our foreign exchange sources and with growing demand in future years the situation is likely become even worse. Also, diesel and petrol engines are the main sources of carbon dioxide, carbon monoxide and un-burnt hydrocarbon emissions and increase in carbon dioxide, carbon monoxide levels in the atmosphere leads to global warming and green house effect. The world is on the brink of energy crises. Due to the shortage of petroleum products and its increasing cost, efforts are on to develop alternative fuels especially, to the diesel oil for fully or partial replacement. It has been found that the vegetable oils are promising fuels because their properties are similar to that of diesel and are produced easily and renewably from the crops. Vegetable oils have comparable energy density, cetane number, heat of vaporization and Stoichiometric air-fuel ratio with that of the diesel fuel[5].

In most of the developed countries, biodiesel is produced from soybean, rapeseed, sunflower, peanut, etc., which are essentially edible in Indian context. Among the various vegetable oil sources, non-edible oils are suitable for biodiesel production. Because edible oils are already in demand and too expensive than diesel fuel. Among the non-edible oil sources, Jatropha, karanjan, Mahua, Neems, sal, Kusum, Nahar, Rice bran and Tumba is identified as potential biodiesel source and comparing with other sources, which has added advantages as rapid growth, higher seed productivity, suitable for tropical and subtropical regions of the world.

The experimental results of various researchers support the use of biodiesel as available alternative to the diesel oil for use in the internal combustion engines. It is also important to note that most of the experiments conducted on biodiesel are mainly obtained from refined edible type oils only. The price of refined oils such as sunflower, soybean oil and palm oil are high as compared to that of diesel. This increases the overall production cost of the biodiesel as well. Biodiesel production from refined oils would not be viable as well as economical for the developing countries like India.

Hence, it is better to use the non-edible type of oils for biodiesel production. In India, non-edible type oil yielding trees such as mahua, sal, linseed, castor, karanji, neem, rubber, jatropha, kusum and cashew are available in large number. The production and utilization of these oils are low at present, because of their limited end usage. Utilization of these oils/ biodiesel as fuels in internal combustion engines is not only reducing the petroleum usage, but also improves the rural economy. Efforts are made here to produce biodiesel from typical unrefined oil (Kusum seed oil) and to use it as the fuel in diesel engines.

\subsection{Characterisation of Kusum Seeds oil:}

In India, Kusum is one of the forest-based tree-borne non-edible oil. The botanical name of Kusum is Schleichera oleosa. S. oleosa is widely found in the sub-Himalayan region, Chattishgarh, throughout central 
and southern India. The estimated availability of kusum seed is about 25,000 oil potential per tones per annum. In the past kusum seed oil was exported from India to Germany. This market has now fallen away. From current production potential 4000 to 5000 tons are collected. kusum seed kernels ( 0.45 lacks of tones of seed) contain $40.3 \%$ of yellowish brown colored oil. The one or two almost round seeds some $1.5 \mathrm{~cm}$ in diameter and weighing between 0.5 and $1.0 \mathrm{~g}$. The oil content is $51-62 \%$ but the yields are $25-27 \%$ in village ghanis and about $36 \%$ oil in expellers. It contains only 3.6 to $3.9 \%$ of glycerin while normal vegetable oil contain $9-10 \%$ glycerine. The viscosity of kusum oil was found to be higher than that of diesel fuel. The high viscosity of kusum oil may be due to its larger molecular weight compared to diesel. The flash point of kusum oil was higher than diesel and hence it is safer to store. It is seen that the kinematic viscosity of kusum oil is $40 \mathrm{cSt}$ at $40^{\circ} \mathrm{C}$ and after blending decreases gradually closer to that of diesel.

FFA composition in Kusum seeds oil: C14:0 Myristic acid (0.01\%), C16:0 Palmitic acid (7.59\%), C16:1 n-7 Palmitoleic acid (1.80\%), C18:1 n-9 Cis Oleic acid (2.83\%), C18:2 n-6 Trans, Linolelaidic acid (49.69\%), C18:2 n-6 Cis Linoleic acid (5.56\%), C18:3 n-3 alpha-Linolenic acid (0.26\%), C20:1 n-9 Eicosenoic acid (29.54\%), C20:2 n-6 Eicosadienoic acid (0.24\%), C21:0 Heneicosanoic acid (0.04\%), C22:0 Behenic acid (1.14\%), C22:1 Erucic acid (1.22\%), C24:0 Lignoceric Acid (0.03\%), C22:6 Docosahexaenoic acid (0.02\%).

\section{Seed Collection Extraction Of Kusum Oil}

The kusum oil used for this study was from Kusum seeds that are collected from seeds market Nagpur (Maharashtra) and expelled in a mechanical expeller and oil from seed kernel was extracted in village Ghani from Achalpur Dist. Amravati (Maharashtra).

\subsection{Kusum oil Methyl Ester (KME) Conversion Process Raw oil Specification}

- $\quad$ Moisture \& insoluble impurities-0.5\%

- $\quad$ Saponification value - 220 to 240

- $\quad$ Sp. Gravity $@ 30^{\circ} \mathrm{C} \quad-0.8653$ to 0.8687

- Iodine value - 48 to 60

- $\quad$ FFA $\%$-- basic $\quad-20 \%$

--Max accept $\quad-30 \%$

- $\quad$ Seed yield $\quad-0.45$ (lack tone)

- Oil content $(\%) \quad-33 \%$

- Oil yield $\quad-0.15$ (lack of tone)

\section{Ttransesterification:}

This process has two separate starting points. If vegetable oils can be obtained that are below $2.5 \%$ FFA, the esterification step is not necessary.

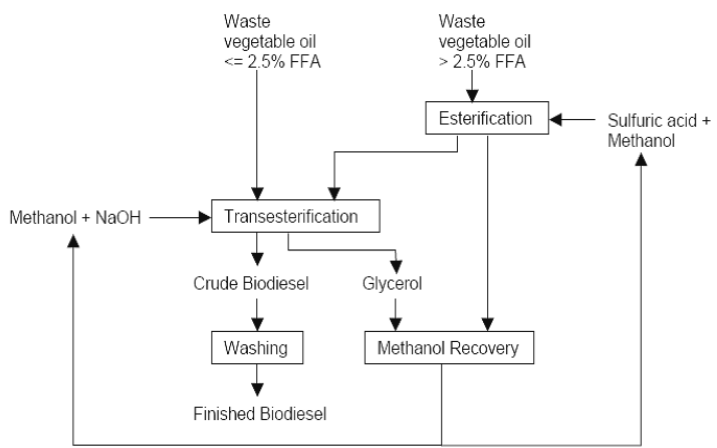

Fig 1: Block Diagram for Biodiesel Process.

Biodiesel is produced by transesterification which is a process of using either ethanol or methanol, in the presence of a catalyst, such as potassium hydroxide, to chemically break the molecule of an oil or fat into an ester and glycerol. This process is a reaction of the oil with an alcohol to remove the glycerine, which is a by product of biodiesel production. The step wise reactions are reversible and a little excess of alcohol is used to shift the equilibrium towards the formation of esters. In presence of excess alcohol, the foreword reaction is pseudo-first order and the reverse reaction is found to be second order.

The first we are taken pretreatment oil temperature is $50-55^{\circ} \mathrm{C}$. The products of the first stage pretreatment oil are used as the input of the alkaline transesterification process. A molar ratio of 6:1(Ratio of oil to methanol) and 10 grms by weight of potassium hydroxide $(\mathrm{KOH})$ is found to give the maximum ester yield. The reaction time is maintains $2 \mathrm{hr}$ at $60^{\circ} \mathrm{C}$. After the reaction is completed, the products are allowed to separate 
into two layers. The lower layer contains impurities and glycerol. This top layer (ester) is separated and purified using distilled water. Hot distilled water $(20 \%$ by volume) is sprayed over the ester and stirred gently and allowed to settle in the separating funnel. The lower layer is discarded and upper layer (purified biodiesel) is separated.

Transesterification of the oil produces methyl esters (biodiesel) and glycerol. The methyl ester layer is a light yellow liquid that is on top or bottom of the glycerol layer, which is dark brown in color. The mixtures may be kept overnight and allowed to separate by gravity. Otherwise, the methyl ester is separated from the glycerol and washed with water and acetic acid until the washing water is neutral. The methyl ester is then dried by heating.

Table1. Properties of Diesel \& KME

\begin{tabular}{|l|c|c|c|c|c|}
\hline Fuel & $\begin{array}{l}\text { Viscosity } \\
\mathbf{a} \mathbf{4 0}^{\mathbf{0}} \mathbf{C} \\
\mathbf{c S t})\end{array}$ & $\begin{array}{l}\text { Density } \\
\mathbf{a} \mathbf{4 0}^{\mathbf{}} \mathbf{C} \\
\left.\mathbf{( K g / \mathbf { m } ^ { 3 }}\right)\end{array}$ & $\begin{array}{l}\text { Flash } \\
\text { point } \\
\left.\mathbf{(}^{\mathbf{0}} \mathbf{C}\right)\end{array}$ & $\begin{array}{l}\text { Fire } \\
\text { point } \\
\left.\mathbf{(}^{\mathbf{0}} \mathbf{C}\right)\end{array}$ & $\begin{array}{l}\text { Calorific } \\
\text { Values } \\
\mathbf{( K J} / \mathbf{K g})\end{array}$ \\
\hline B100\% & 14.2 & 850 & 150 & 157 & 41,650 \\
\hline B80\% & 12.03 & 840 & 109 & 117 & 41,720 \\
\hline B60\% & 9.73 & 830 & 88 & 93 & 41,790 \\
\hline B40\% & 8.00 & 820 & 85 & 89 & 41,860 \\
\hline B20\% & 3.33 & 809 & 80 & 84 & 41,930 \\
\hline Raw oil & 40.36 & 860 & 225 & 231 & 38,140 \\
\hline Diesel & 3.8 & 829 & 85 & 63 & 42990 \\
\hline
\end{tabular}

\section{Experimental Setup}

A single cylinder 4-stroke air-cooled diesel engine is used. An electric dynamometer is used for loading the engine. The parameters related to the performance of the engine are: specific fuel consumption, the thermal efficiency, brake power, exhaust gas temperature and smoke density were evaluated for each fuel Blends and at different engine loading.

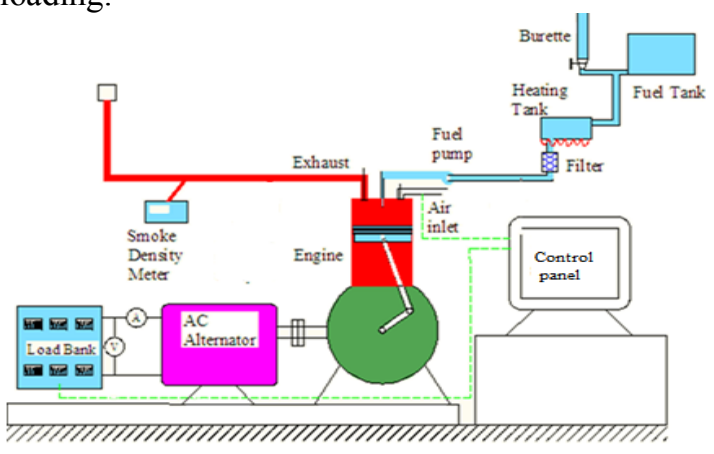

Figure 2: Experimental set up

The arrangement is to be made on the engine for the measurement of fuel consumption, and temperatures at different points, the engine will be attached with a generator; maximum load capacity of $5 \mathrm{~kW}$ for performance study and at the constant speed. As the engine is water cooled water supply has to be maintaining during experimentation for engine body cooling. The engine is to be equipped with several measuring instruments thermocouples installation with its indicators mounted on the control panel, non contact type tachometer system, smoke meter.

Table 1: Specification of engine used

\begin{tabular}{|l|l|}
\hline Name of Engine & Comet \\
\hline General details & $\begin{array}{l}\text { Single cylinder, Four-stroke, } \\
\text { water cooled, DI Diesel engine. }\end{array}$ \\
\hline Bore & $102 \mathrm{~mm}$ \\
\hline Stoke & $116 \mathrm{~mm}$ \\
\hline Comp. ratio & $18.8: 1$ \\
\hline $\begin{array}{l}\text { Rated power- } \\
\text { BHP/kW }\end{array}$ & $10 / 7.4$ \\
\hline Rated speed & $1500 \mathrm{rpm}$ \\
\hline $\begin{array}{l}\text { Swept volume } \\
\text { Sp. Fuel cons. } \\
\text { gms/kWh }\end{array}$ & 948 \\
\hline
\end{tabular}


Experiments were performed with diesel fuel and blends of kusum oil methyl ester with diesel, namely B $20 \%$, B $40 \%$, B $60 \%$, B $80 \%$ and B100\%. Experiments are initially carried out on the engine using diesel fuel in order to provide base line data. The fuel consumption, exhaust gas temperature and smoke were measured and recorded for different loads. Similar procedures were repeated for the B20\%, B40\%, B60\%, B80\% and B100\% different blends.

\subsection{Thermal Efficiency}

\section{Results And Discussion}

Thermal efficiency is the ratio between the power output and the energy introduced through fuel injection. Fig.3. Shows that the variation of brake thermal efficiency with load for diesel and different blends of the kusum oil methyl ester. In all the cases as load increases the break thermal efficiency increases. It is observed that each blends of the kusum oil yields higher brake thermal efficiency compared to that of diesel and it is maximum for B $80 \%$ than other blend. This increase in brake thermal efficiency for kusum oil blends compared to diesel may be due to the energy of the kusum oil entering engine is considerably low because of lower heating value, which results in higher brake thermal efficiency. Also the possible reason may be more complete combustion, and additional lubricity of biodiesel. The molecule of the biodiesel has some oxygen that takes part in combustion and results in complete combustion.

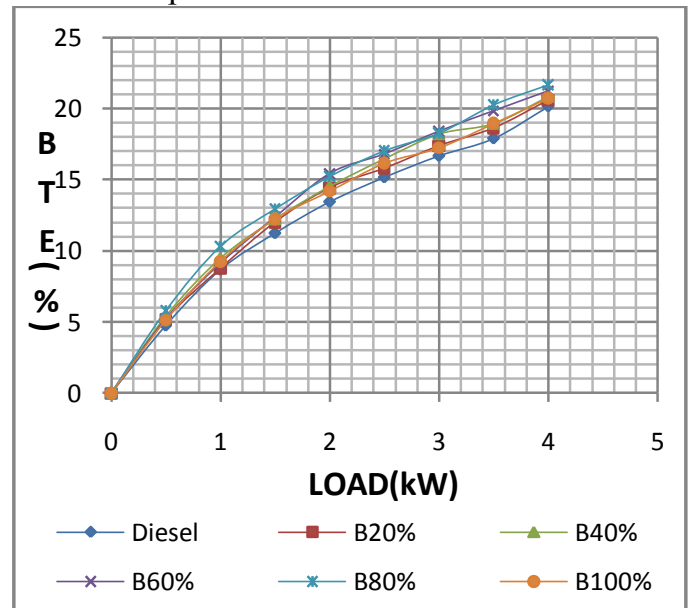

Figure 3: Variation of BTE with load

\subsection{Exhaust Gas Temperature}

Fig. 4. Shows the variation of exhaust gas temperature with respect to load for diesel and blends of kusum oil methyl ester. It is observed that the exhaust gas temperature increases as load increases because more fuel burnt at higher loads to meet the power requirement. The exhaust gas temperature for all the blends of the kusum oil is higher compared to that of diesel and it is higher for B40\%. This may be attributed to oxygen content of the kusum oil, which improves the combustion and thus may increase the exhaust gas temperature.

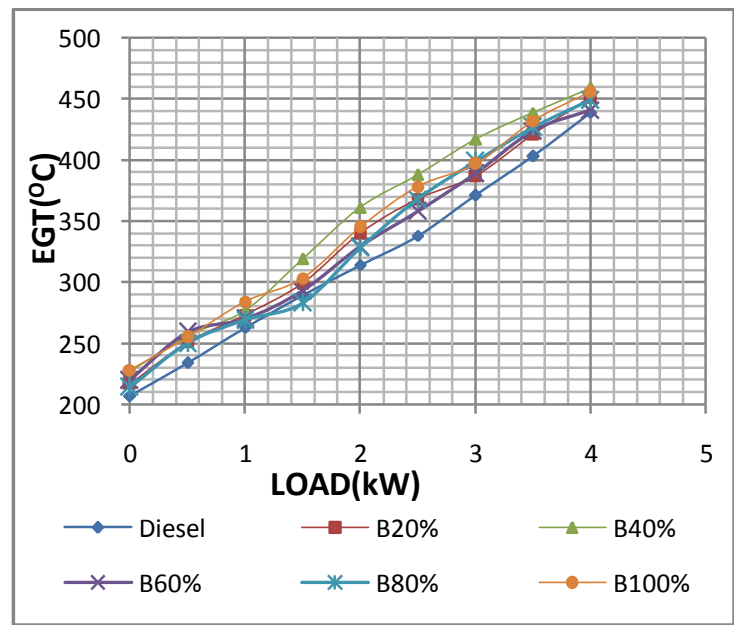

Figure 4: Variation of EGT with load 


\subsection{Smoke density}

Fig. 4 shows the variation of smoke density with respect to load for kusum oil blends and diesel. It is observed that smoke density for kusum oil blends is generally lower than that of diesel. However, at lower loads B100\% kusum oil showed slightly higher smoke density than other blends but lower than diesel. At higher loads all the blends of kusum oil showed better emission performance than that of diesel. The possible reason for lower smoke density of kusum oil blends may be better combustion of fuel due to oxygen atom present in molecules of oil itself.

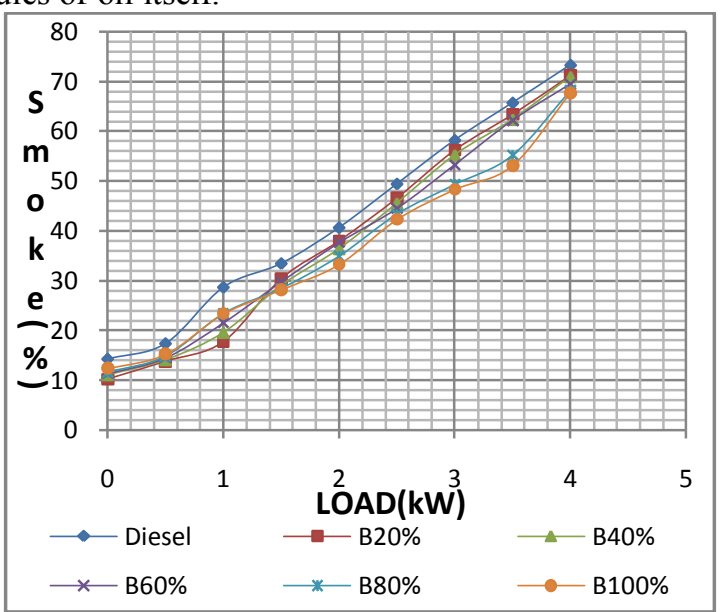

Figure 5: Variation of Smoke with load

\subsection{Part Load \& Peak Load Performance of Engine}

The performance parameter that is brake thermal efficiency, exhaust gas temperature and smoke density of the engine at the part load $2 \mathrm{Kg}$ and peak load $4 \mathrm{Kg}$ are compared and studied.

\subsubsection{Thermal Efficiency}

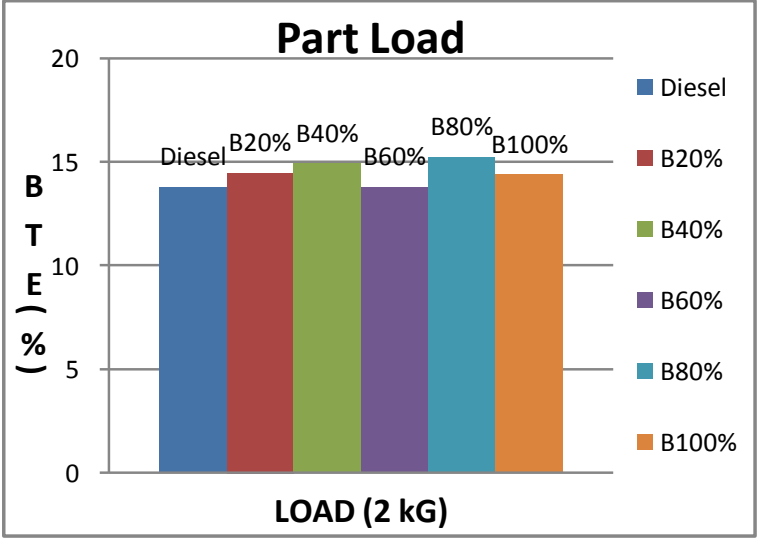

Figure 6a: Variation of BTE with Part Load for diesel \& blends of kusum oil

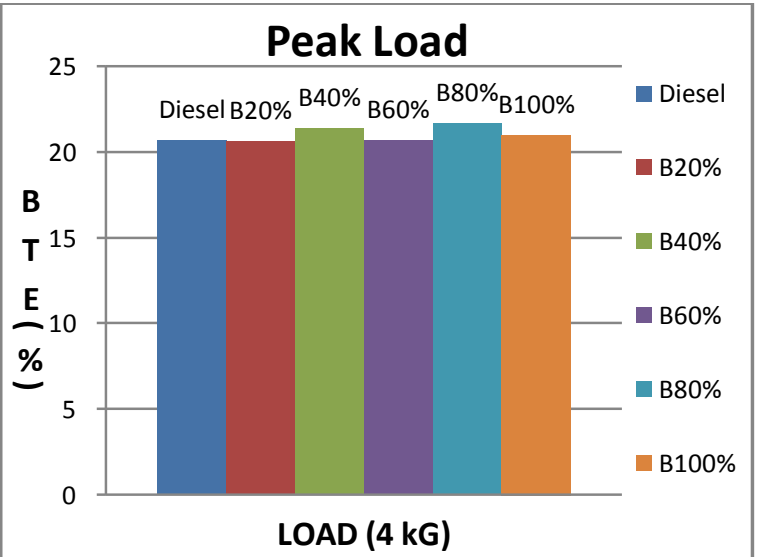

Figure 6b: Variation of BTE with Peak Load for diesel \& blends of kusum oil

From above fig. 6a $\& 6$ b it observed that the part load and peak load efficiency for kusum oil blends is higher compared to diesel. The maximum efficiency was obtained for B80\%(15.25\%), B40\%(14.90\%) at part 
load and B80\%(21.69\%), B40\%(21.37\%) at peak load and these value comparable with diesel are $13.79 \%$ \& $20.66 \%$ respectively. From fig. $6 \mathrm{a}$ it is observed that brake thermal efficiency for kusum oil \& its blends in comparison to diesel is a better option for part load on witch most engine runs.

\subsubsection{Exhaust Gas Temperature}

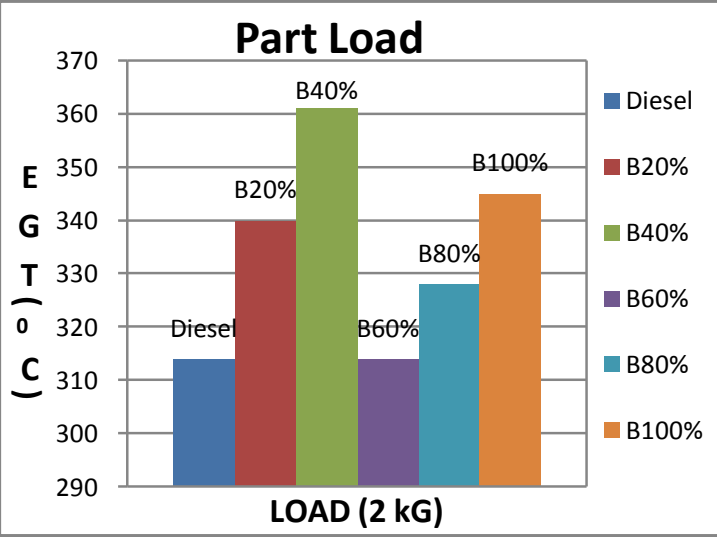

Figure 7a: Variation of exhaust gas temperature with Part Load for Diesel \& Various Blends.

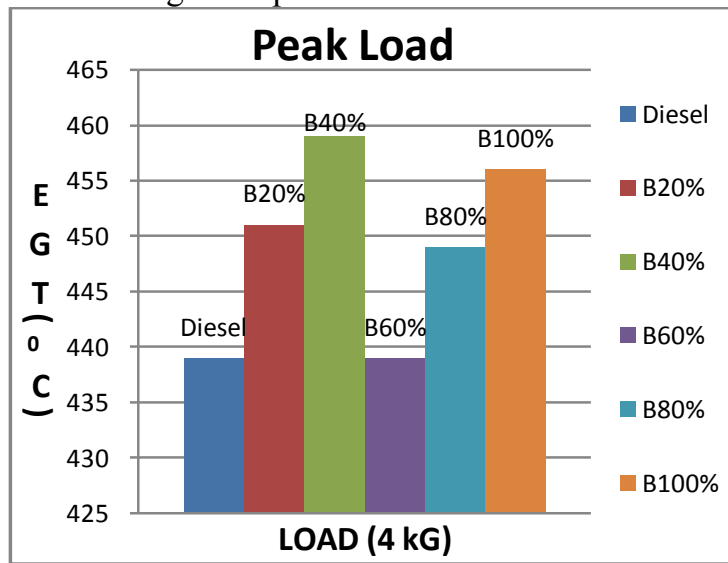

Figure 7a: Variation of exhaust gas temperature with Peak Load for Diesel \& Various Blends.

From fig. 7a \& 7b that the EGT at part \& peak load for B40\% is high than diesel and other blends. And for all blends at both loads it shows upward trend than the diesel. Kusum oil contents oxygen which enables the combustion process and hence the exhaust temperature are higher.

\subsubsection{Smoke Density}

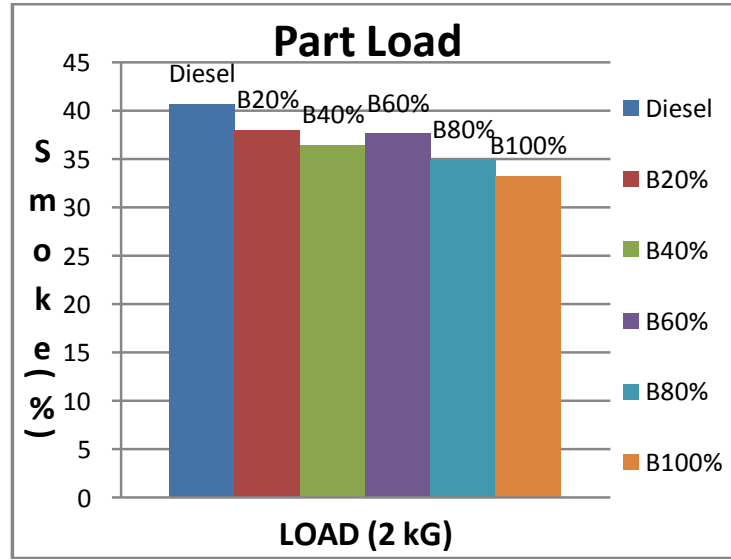

Figure 8a: Variation of Smoke density with Part Load for Diesel \& Various Blends 


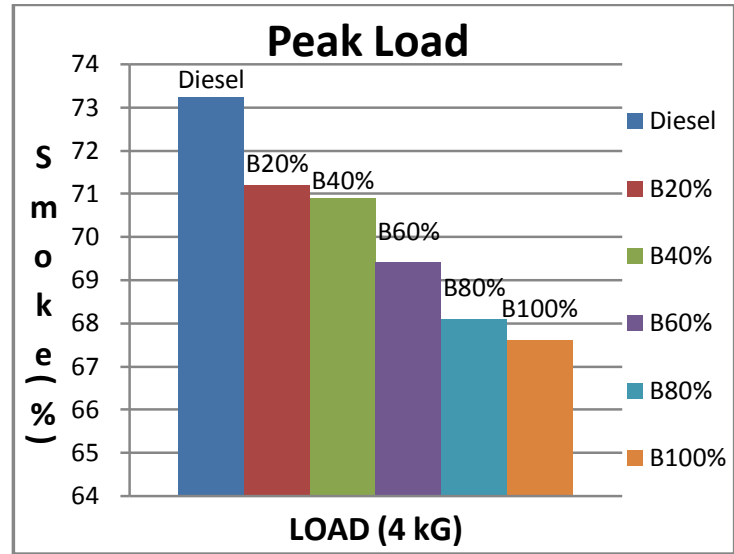

Figure 8b: Variation of Smoke density with Peak Load for Diesel \& Various Blends

From fig.8a it is observed that the variation of Smoke density at part load is less but nearly close to diesel for $\mathrm{B} 20 \%$ \& B $60 \%$ and is lower for all blends. And at peak load from fig. $8 \mathrm{~b}$ it is observed that smoke density trend is continuously decreasing as blend percentage increases. It is lower compared to diesel attributed to the complete combustion of fuel as oxygen atoms takes part in combustion processes.

\section{Conclusions}

In this work a single cylinder four stroke compression engine when it is powered by neat and blends of biodiesel (methyl ester kusum oil)-diesel fuel at various loading conditions and its performance and emission characteristics are analysed. The concentration of biodiesel blends found to improve the thermal efficiency. $\mathrm{KME} \mathrm{B} 20 \%$, B $40 \%, 620 \%, \mathrm{~B} 80 \%$ and $\mathrm{B} 100 \%$ biodiesel blends gives good improvement in brake thermal efficiency of diesel engine at different load conditions. Also, reduced emission and brake specific fuel consumption is found out while using blending. Higher the concentration of biodiesel blend, higher is the reduction of smoke density in exhaust gas. The exhaust gas temperature increased as a function of concentration of biodiesel in the blend.

The present experimental results supports that methyl esters of kusum seed oil as biodiesel can be successfully used in existing diesel engines without any modifications. Use of the biodiesel as partial diesel substitute can boost the farm economy, reduce uncertainty of fuel availability in rural and remote areas where grid power is not available, vegetable oil can play a vital role in decentralized power generation for irrigation and electrification and make farmers more self-reliant. Also, this help in controlling air pollution to a great extent.

\section{NOMENCLATURES \\ BSFC Brake specific fuel consumption \\ CI Compression Ignition \\ CR Compression ratio \\ EGT Exhaust gas temperature \\ BTE Brake thermal efficiency \\ KME Kusum oil Methyl Ester}

\section{References}

[1] Ayhan Demirba, Department of Chemical Education, Karadeniz Technical University "Biodiesel fuels from vegetable oils via catalytic and non-catalytic supercritical alcohol transesterifications and other methods: a survey”, PK 216, Trabzon 61035, Turkey.

[2] Mallela Gandhi, N. Ramu and S. Bakkiya Raj "methyl ester production from schlichera oleosa" Mallela et al., IJPSR, 2011 ; Vol. 2(5): 1244-1250

[3] Biodiesel production: a review1 Fangrui Maa, Milford A. Hannab,* a Department of Food Science and Technology, University of Nebraska, Lincoln, NE, USA b Industrial Agricultural Products Center, University of Nebraska, 211 L.W. Chase Hall, Lincoln, NE 68583-0730, USA

[4] Lohith.N, Dr. R.Suresh, Yathish.K.V "Experimental Investigation of Compressed Ignition Engine Using Karanja Oil Methyl Ester (KOME) as Alternative Fuel". / International Journal of Engineering Research and Applications (IJERA) ISSN: 2248-9622Vol. 2, Issue4, July-August 2012, pp.1172-1180

[5] S. Kalligeros, F. Zannikos, S. Stournas, E. Lois, G.Anastopoulos, Ch. Teas and F. Sakellaropoulos "An investigation of using biodiesel/marine diesel blends on the performance of a stationary diesel engine".

[6] Deepak Agarwal, Avinash Kumar Agarwal, "Performance and emissions characteristics of Jatropha oil (preheated and blends) in a direct injection compression ignition engine". Applied Thermal Engineering 27 (2007) 2314-2323.

[7] M.C.Navindgi, Maheswar Dutta and B. Sudheer Prem "Performance evaluation, emission characteristic and economic analysis of four non-edible straight vegetable oils on a single cylinder CI engine". Kumar ARPN Journal of Engineering and Applied Sciences Voi.7,No.2, Feb2012 
[8] Magín Lapuerta, Octavio Armas and José Rodríguez-Fernández Escuela Técnica "Effect of biodiesel fuels on diesel engine emissions" Superior de Ingenieros Industriales, University of Castilla-La Mancha, Avda. Camilo José Cela, s/n. 13071 Ciudad Real, Spain

[9] Sharanappa Godiganur, C.H. Suryanarayana Murthy, Rana Prathap Reddy, 2009,"6BTA 5.9 G2-1 Cummins engine performance and emission tests using methyl ester mahua (Madhuca indica) oil/diesel blends". Renewable Energy 34, $2172-2177$.

[10] Anh N. Phan and Tan M. Phan "Biodiesel production from waste cooking oils"School of Chemical Engineering and Advanced Materials, Newcastle University, NE1 7RU, UK

[11] S.K.Acharya, M.K.Mohanty R.K.Swain "Kusum Oil as a Fuel for Small Horse Power Diesel Engine" International Journal of Engineering and Technology Vol. 1, No.3, August, 2009 ISSN: 1793-8236

[12] Murat Karabektas, Gokhan Ergen, Murat Hosoz, 2008, "The effects of preheated cottonseed oil methyl ester on the performance and exhaust emissions of a diesel engine". Applied Thermal Engineering 28, 2136-2143.

[13] M. C. Navindgi1, Maheswar Dutta2 and B. Sudheer Prem Kumar3 "performance evaluation, emission characteristics and economic analysis of four non-edible straight vegetable oils on a single cylinder CI engine" vol. 7, no. 2, february 2012 ARPN Journal of Engineering and Applied Sciences. [14] Avinash Kumar Agarwal and K. Rajamanoharan, 2009, "Experimental investigations of performance and emissions of Karanja oil and its blends in a single cylinder diesel engine". Applied Energy 86, 106-112.

[15] Sagar Pramodrao Kadu and Rajendra H. Sarda 2010, "Experimental Investigations on the Use of Preheated Neat Karanja Oil as Fuel in a Compression Ignition Engine". International Journal of Mechanical and Materials Engineering, $145-149$.

[16] Canakci, M. and J. Van Gerpen, "A Pilot Plant to Produce Biodiesel from High Free Fatty Acid Feedstocks",ASAE Transactions 46(4) 2003 pp. 945-954 This paper was also published as SAE Paper No. 01-6049, 2001.

[17] Hanbey Hazar and Huseyin Aydin, 2010, "Performance and emission evaluation of a CI engine fueled with preheated raw rapeseed oil (RRO)-diesel blends”, Applied Energy 87, 786-790.

[18] Canakci, M. and J. Van Gerpen, "The Performance and Emissions of a Diesel Engine Fuelled with Biodiesel from Yellow Grease and Soybean Oil", ASAE Paper No. 01-6050, 2001 